\title{
Woven coronary artery: a case report and literature review
}

\author{
S.-M. Yuan \\ $1^{\text {st }}$ Hospital of Putian, Teaching Hospital, Fujian Medical University, Putian, Fujian Province, People's Republic of China
}

[Received 9 April 2013; Accepted 17 May 2013]

Woven coronary artery is extremely rare. It is characterised by thin channels arising from the coronary artery and reanastamosis at the distal portion. A 62-year-old man was diagnosed of coronary artery disease. Coronary angiography showed 3-vessel coronary artery disease. The distal right coronary artery derived 3 twisting thin channels, and the inferior thin channel sprouted second-class thin channels, which then reanstomosed distally. He received off-pump coronary artery bypass. The present patient had woven coronary artery with a more complex configuration of thin channels different from the previously reported cases. (Folia Morphol 2013; 72, 3: 263-266)

Key words: coronary artery disease, off-pump coronary artery bypass, internal mammary-coronary artery anastomosis

\section{INTRODUCTION}

Woven coronary artery is extremely rare. It is characterised by thin channels arising from the coronary artery and reanastamosis at the distal portion of the coronary artery [8]. Woven coronary artery is a benign condition, usually with normal blood flow through the coronary artery [9]. It is interpreted as a congenital anomaly of the coronary artery. However, the incidence of this condition is undetermined [8]. Only 10 patients were reported to have woven coronary artery in the medical literature. In this report, an alternative woven coronary artery was supplemented and the clinical implications of this condition were briefly discussed.

\section{CASE REPORT}

A 62-year-old man was referred to our hospital due to chest distress and precordial pain for 5 days. Physical examination revealed that his blood pressure was $180 / 110 \mathrm{~mm} \mathrm{Hg}$ on admission. His blood troponin T was $9.26 \mathrm{ng} / \mathrm{mL}$ (normal 0-0.04 ng/mL), hypersensitive C-reactive protein was $5.90 \mathrm{mg} / \mathrm{L}$ (normal $0-3.0 \mathrm{mg} / \mathrm{L}$ ), and $\beta_{2}$-microglobulin was $3.34 \mathrm{mg} / \mathrm{L}$ (normal 0.8-3.16 mg/L). Rales were audible over the lungs, and a 2/6 grade diastolic murmur was heard at the apex. Electrocardiogram showed ST depression in leads II, III, aVF and V4-V6. Echo-cardiography demonstrated left ventricular hypokinesis in the posterior and inferior walls and mild mitral insufficiency with an ejection fraction of $54 \%$. Coronary angiography showed the distal left main coronary artery $50 \%$ stenosis, diffuse narrowing of the left anterior descending coronary artery $30 \mathrm{~mm}$ long with a maximal $95 \%$ stenosis, and proximal right coronary artery $50 \%$ diffuse stenosis. The distal portion of the right coronary artery derived three thin channels which were twisting but not intertwining, and the inferior thin channel sprouted second-class thin channels, which then reanstomosed distally (Fig. 1). After medical treatment, the patients' symptoms were relieved, and his blood pressure was normal. He received off-pump coronary artery bypass with a left internal mammary artery-saphenous vein I-graft to the left anterior descending coronary artery, and a sequential saphenous vein grafts to the diagonal and first obtuse marginal branches. He was doing well after the operation. 


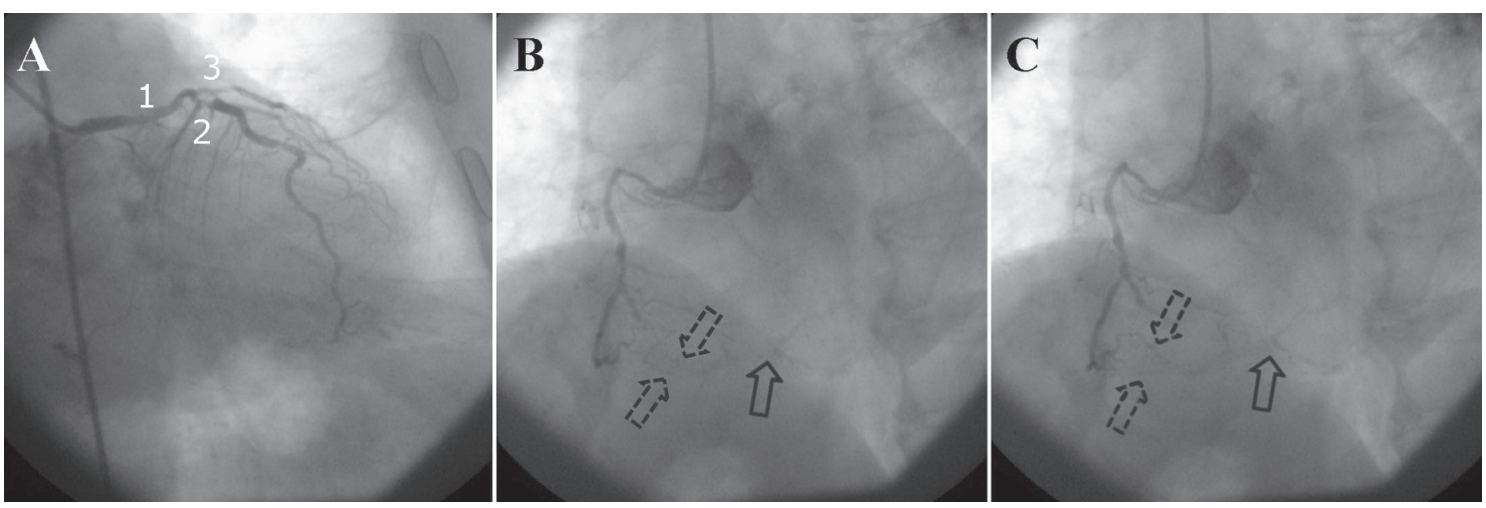

Figure 1. Coronary angiogram showed (A) long narrowing of left main coronary artery (1), severe stenosis of the left anterior descending coronary artery (2) and of the circumflex branch (3); B, C. Woven right coronary artery derived 3 thin channels with the inferior one sending out second-class thin channels (dashed arrows), which then reanastomosed distally (solid arrow).

\section{DISCUSSION}

Ten patients with woven coronary artery were reported in the literature [1-7, 9]. There were totally 11 patients including the present case. Their demographic data were listed in Table 1. This patient setting was comprised of 10 adults and one 9-month-old infant. Their mean age was $49.1 \pm 17.4$ years (median: 55 years; range: 9 months to 62 years). Eight patients were males, 2 were females and 1 patient's gender was not given.

There were 14 segments of woven coronary arteries in the 11 patients: $10(90.9 \%)$ patients had 1 woven segment, and $1(9.1 \%)$ patient had 4 woven segments. The diagnoses were made on coronary angiography in all 11 patients. The woven coronary arteries were $7(50 \%)$ right coronary arteries, 4 (28.6\%) circumflex branches, 2 (14.3\%) left anterior descending coronary arteries, and $1(7.1 \%)$ left obtuse marginal branch. The woven segments were located in the distal, proximal, mid, mid-distal, and proximal-mid portion of the coronary arteries in $5(35.7 \%), 4(28.6 \%), 2(14.3 \%)$, $2(14.3 \%)$ and $1(7.1 \%)$, respectively. The woven coronary arteries were configured as intertwined in $7(50 \%)$, twisting in $5(35.7 \%)$, paralleling in $1(7.1 \%)$, and in a fashion of "figure of 8 " in $1(7.1 \%)$, respectively. The thin channels of the woven coronary arteries were double in $8(57.1 \%)$, multiple in $5(35.7 \%)$, and triple in $1(7.1 \%) \mathrm{seg}$ ment of the coronary arteries, respectively. The woven coronary arteries were with normal flow in all 11 patients. Occlusion of otherwise coronary arteries developed in 8 patients and coronary artery dilation secondary to Kawasaki disease in
1 patient. Four of the patients with coronary artery occlusion received percutaneous coronary angioplasty and 2 patients underwent coronary artery bypass grafting. All patients survived at a maximal follow-up of 4 years.

Woven coronary arteries often have thin channels and reanastomosis at the distal part of the coronary artery. However, in the exceptional case, reanastomosis may be absent at the farther distal portion of the coronary artery [2]. Coronary angiography is the gold standard for the diagnosis of woven coronary artery [8]. In spite of abnormal coronary artery structures, the blood flow and the myocardial contractility are normal $[5,8]$. The thin channels were occasionally misdiagnosed as a dissected atherosclerotic plaque with thrombus formation [4, 6]. Kaya et al. [4] reported that the thin channels were not visualised until the third coronary angiography 3 years after coronary artery bypass grafting.

The present patient had woven coronary artery with a more complex configuration of thin channels different from the previously reported cases.

\section{CONCLUSIONS}

Woven coronary artery is an extremely rare lesion. The thin channels that the woven coronary arteries form may sometimes lead to a misdiagnosis. As woven coronary artery is not a substantially stenosed coronary artery and therefore does not require special treatment, care must be taken when the physicians encounter such a lesion and differential diagnosis with a dissected atherosclerotic plaque with thrombus formation is warranted. 


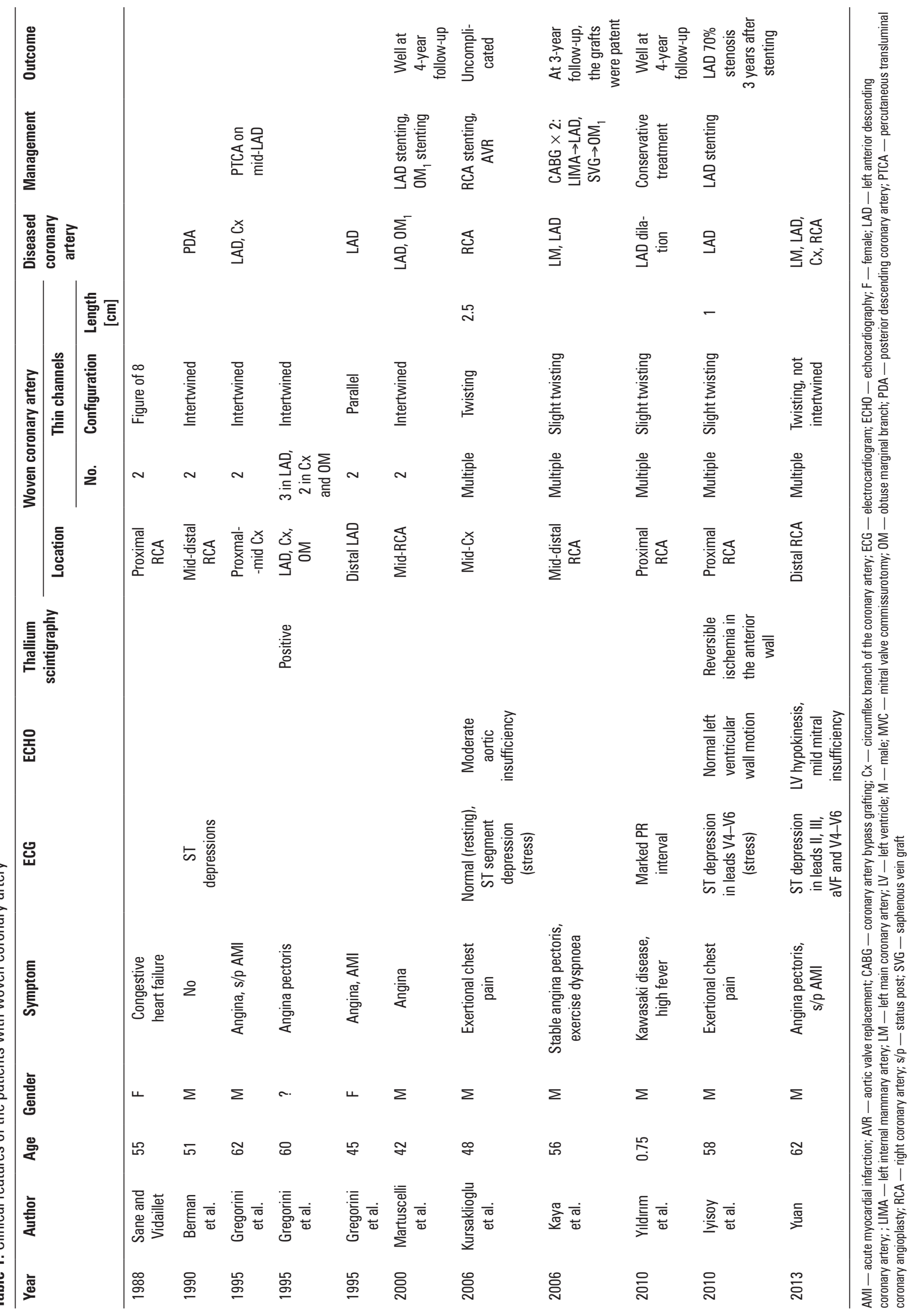




\section{REFERENCES}

1. Berman AD, Kim D, Baim DS (1990) "Woven" right coronary artery: case report and therapeutic implications. Cathet Cardiovasc Diagn, 21: 258-259.

2. Gregorini L, Perondi R, Pomidossi G, Saino A, Bossi IM, Zanchetti A (1995) Woven left coronary artery disease. Am J Cardiol, 75: 311-312.

3. Iyisoy A, Celik T, Yuksel UC, Isik E (2010) Woven right coronary artery: a case report and review of the literature. Clin Cardiol, 33: E43-E45.

4. Kaya D, Kilit C, Onrat E (2006) An uncommon congenital anomaly of coronary arteries misdiagnosed as intracoronary thrombus: woven coronary artery disease. Anadolu Kardiyol Derg, 6: 383-384.

5. Kursaklioglu H, lyisoy A, Celik T (2006) Woven coronary artery: a case report and review of literature. Int J Cardiol, 113: $121-123$.
6. Martuscelli E, Romeo F, Giovannini M, Nigri A (2000) Woven coronary artery: differential diagnosis with diffuse intracoronary thrombosis. Ital Heart J, 1: 306-307.

7. Sane DC, Vidaillet HJ Jr. (1988) "Woven" right coronary artery: a previously undescribed congenital anomaly. Am J Cardiol, 61: 1158.

8. Yıldııım A, Oğuz D (2011) Woven coronary artery. In: Suna F. Kiraç ed. Advances in the diagnosis of coronary atherosclerosis. InTech, 297-304. Available from: http:// www.intechopen.com/articles/show/title/woven-coronary-artery.

9. Yildirim A, Oğuz D, Olguntürk R (2010) Woven right and aneurysmatic left coronary artery associated with Kawasaki disease in a 9-month-old patient. Cardiol Young, 20: 342-344. 